\title{
Reorganization of cytoskeletal proteins and prolonged life expectancy caused by hepatocyte growth factor in a hamster model of late-phase dilated cardiomyopathy
}

Haruhiko Kondoh, MD, ${ }^{a}$ Yoshiki Sawa, MD, ${ }^{a}$ Norihide Fukushima, MD, ${ }^{a}$ Goro Matsumiya, MD, ${ }^{\text {a }}$ Shigeru Miyagawa, MD, ${ }^{a}$ Satoru Kitagawa-Sakakida, MD, ${ }^{\mathrm{b}}$ Imran A. Memon, MD, ${ }^{a}$ Naomasa Kawaguchi, MD, ${ }^{c}$ Nariaki Matsuura, MD, ${ }^{\mathrm{c}}$ and Hikaru Matsuda, MDa

\footnotetext{
From the Division of Cardiovascular Surgery, Department of Surgery, ${ }^{a}$ Department of Molecular Pharmacology, ${ }^{\mathrm{b}}$ Department of Pathology, School of Allied Health Science, Faculty of Medicine, ${ }^{\text {c Osaka Univer- }}$ sity Graduate School of Medicine, Osaka, Japan.
}

This work was supported by a Grant-in-Aid for Scientific Research in Japan.

Received for publication July 5, 2004; revisions received Oct 31, 2004; accepted for publication Nov 2, 2004.

Address for reprints: Hikaru Matsuda, MD, Division of Cardiovascular Surgery, Department of Surgery, Osaka University Graduate School of Medicine, 2-2 Yamadaoka, Suita, Osaka 565-0871, Japan (E-mail: matsuda@surg1.med.osaka-u.ac.jp).

J Thorac Cardiovasc Surg 2005;130:295-302 $0022-5223 / \$ 30.00$

Copyright (C) 2005 by The American Association for Thoracic Surgery

doi:10.1016/j.jtcvs.2004.11.001
Objective: It has been postulated recently that changes in cytoskeletal and sarcolemmal proteins initiate a final common pathway for contractile dysfunction in dilated cardiomyopathy. In ischemic cardiomyopathy, hepatocyte growth factor plays an important role in reorganizing the impaired cytoskeletal proteins in several cell types. We have tested the hypothesis that hepatocyte growth factor might improve life expectancy through modification of the molecular process that contributes to impairment in dilated cardiomyopathy.

Methods: Adult male 27-week-old BIO TO-2 hamsters, which show moderate cardiac remodeling, were divided into treatment groups that received (1) hemagglutinating virus of Japan liposomes containing human hepatocyte growth factor cDNA (H group), (2) culture medium (C group), or (3) sham operation ( $\mathrm{S}$ group).

Results: After the operation, echocardiography demonstrated that the enlarged left ventricular end-systolic dimension and decreased fractional shortening were significantly attenuated in the $\mathrm{H}$ group compared with the $\mathrm{C}$ group. There was significantly less myocardial fibrosis in the $\mathrm{H}$ group compared with the $\mathrm{C}$ group. Immunohistochemical analysis showed alpha-dystroglycan and alpha- and betasarcoglycan expression in the basement membrane beneath the cardiomyocytes in the $\mathrm{H}$ group, whereas no expression of these proteins was seen in the $\mathrm{C}$ group. The 40-week survival was significantly better in the $\mathrm{H}$ group than in the $\mathrm{C}$ and $\mathrm{S}$ groups.

Conclusion: An improved survival associated with transient reorganization of the cytoskeletal proteins and reduction in myocardial fibrosis was achieved by hepatocyte growth factor treatment in an adult hamster model of dilated cardiomyopathy. The results suggest a therapeutic potential of hepatocyte growth factor in the treatment of dilated cardiomyopathy.

$\mathrm{D}$ ilated cardiomyopathy (DCM) is one of the most common causes of chronic heart failure. ${ }^{1}$ Patients have recently started to show longer survival times because of improved medical therapies, such as angiotensin-converting enzyme inhibitors and beta-blockers, and interventions, such as implantable defibrillators and left ventricular assist devices (LVADs). ${ }^{2}$ However, the prognosis is still poor, and cardiac transplantation is the best treatment for DCM in advanced cases. ${ }^{3,4}$ Unfortunately, cardiac transplantation has limitations, such as donor shortages, rejection, and infection. ${ }^{5}$ Therefore, novel strategies are still desired.

DCM pathology is characterized by myocardial remodeling, which is associated with changes in the cytoskeletal and sarcolemmal proteins in cardiomyocytes, leading to a reduction in the number and function of these cells. ${ }^{6}$ These processes are potentially reversible, given that some patients with DCM exhibit restoration of their cytoskeletal proteins after LVAD-mediated unloading support, which is associated with sufficient recovery of the myocardium to allow LVAD removal..$^{7-9}$ 
Therefore, although the variable response to LVAD removal may reflect a combination of abnormalities, we speculated that a good therapeutic strategy for DCM would be to restore the disrupted cytoskeletal and sarcolemmal proteins.

Hepatocyte growth factor (HGF) is a multipotent growth factor with antifibrotic and angiogenic effects, and it activates the matrix degradation pathway. ${ }^{10,11}$ In particular, Taniyama and colleagues ${ }^{12}$ showed that transfection with the HGF gene by echocardiography-guided direct injection attenuates the progression of DCM in a hamster model. However, this preliminary study had limitations, in that the precise mechanism of the HGF effect and its impact on the prognosis were still unknown. A recent report showed that in a myocardial infarction model, HGF induced an appropriate microenvironment for extracellular matrix (ECM) remodeling, including the strong expression of cytoskeletal proteins such as alpha- and beta-dystroglycan. ${ }^{13}$ Moreover, both these dystroglycans are major components of the dystrophin-associated glycoprotein complex (DGC), which plays important roles in signal transduction and the protection of cells during heart muscle contraction. ${ }^{4,14}$ Given this body of evidence, we hypothesized that HGF might induce restoration of the impaired cytoskeletal proteins and morphologic improvement, such as a reduction of myocardial fibrosis, leading to an improvement in life expectancy. In this study, we addressed the following specific questions: (1) Can HGF induce morphologic improvement, such as reduction of the myocardial fibrosis, and restoration of the impaired cytoskeletal proteins in DCM? (2) Can HGF improve the life expectancy for this disorder?

\section{Methods}

\section{Experimental Animals}

Male BIO TO-2 hamsters (Bio Breeders, Fitchburg, Mass), 27 weeks old, were used for this study. Humane animal care was used, in compliance with the "Principles of Laboratory Animal Care," formulated by the National Society for Medical Research, and "Guide for the Care and Use of Laboratory Animals," prepared by the National Institutes of Health (Publication No. 86-23, revised 1985). The animals were divided into 3 treatment groups: The first received injections of hemagglutinating virus of Japan (HVJ) liposomes containing human HGF cDNA ( $\mathrm{H}$ group, $\mathrm{n}=38$ ); the second received injections of culture medium ( $\mathrm{C}$ group, $\mathrm{n}=29$ ); and the third received thoracotomy alone ( $\mathrm{S}$ group, $\mathrm{n}=18$ ). A total of 13 hamsters in the $\mathrm{H}$ group and 10 hamsters in the $\mathrm{C}$ group were used for histologic analysis at 2, 4, and 8 weeks after the operation. Six animals in the $\mathrm{H}$ group and 3 in the $\mathrm{C}$ group were sacrificed for measurement of human HGF concentration at 1 and 3 weeks. The number of animals sacrificed at each time point is shown in the figure legends. The remaining hamsters $(\mathrm{n}=19$ for the $\mathrm{H}$ group, $\mathrm{n}=16$ for the $\mathrm{C}$ group, and $\mathrm{n}=18$ for the $\mathrm{S}$ group) were used for the evaluation of cardiac function or prognosis.

\section{Human HGF Gene Preparation for Injection}

The human HGF cDNA was inserted into the NotI site of the pCU-SR $\alpha$ expression vector. ${ }^{15}$ The preparation of the liposome complex with HVJ was described previously. ${ }^{16}$ In brief, phosphatidylserine, phosphatidylcholine, and cholesterol were mixed. The dried lipid was hydrated in a balanced salt solution containing human HGF cDNA. Liposomes were prepared by shaking and sonication of the mixture. The liposome suspension was mixed with HVJ. Free HVJ was separated from the HVJ-liposome complex by sucrose density gradient centrifugation. The top layer of the sucrose gradient was collected for use.

\section{Transfection of the Human HGF Gene}

Hamsters were anesthetized by intraperitoneal injection of pentobarbital (50 mg/kg body weight). The anesthetized hamsters were intubated, and positive-pressure ventilation was maintained with a ventilator (model SN-480-7 Shinano, Tokyo, Japan). The respiratory rate was set at 50 cycles $/ \mathrm{min}$, with a tidal volume of $2.0 \mathrm{~mL}$ of room air. The heart was exposed through a $2.5-\mathrm{cm}$ left lateral thoracotomy. Approximately $0.2 \mathrm{~mL}$ of the HVJ-liposomeplasmid complex (including $320 \mu \mathrm{g}$ of the human HGF cDNA) was injected with a $30 \mathrm{G}$ tuberculin syringe into 1 site in the RV and 3 sites in the LV wall (anterior free wall, apex, and posterior wall). Control hamsters received injections of $0.2 \mathrm{~mL}$ of the culture medium into the same sites as for the HGF injections. One and 3 weeks after the transfection, the concentration of human HGF in the cardiac tissue was measured by enzyme-linked immunosorbent assay using an anti-human HGF monoclonal antibody (Institute of Immunology, Tokyo, Japan) to document the successful transfection of HGF vector into the myocardium. The antibody against human HGF reacts only with human HGF and not with hamster HGF. ${ }^{17}$

\section{Measurement of Hamster Cardiac Function}

Isoflurane was used for anesthesia during echocardiographic measurements. The concentration of the anesthetic was reduced to $1 \%$ and maintained for 20 minutes to stabilize the hemodynamics. Echocardiography was performed with a commercially available echocardiograph, SONOS 5500 (Agilent Technologies, Palo Alto, Calif). A $12-\mathrm{MHz}$ annular array transducer was used. M-mode echocardiograms were recorded, and the left ventricular endsystolic dimension (Ds), left ventricular end-diastolic dimension (Dd), and fractional shortening (FS) were determined. The reader was blinded to the study group.

\section{Histologic Analyses}

LV myocardium specimens were obtained 2, 4, and 8 weeks after the operation. Transverse sections of the hearts (2- $\mu \mathrm{m}$ thick) were fixed with $10 \%$ buffered formalin, embedded in paraffin, and subjected to hematoxylin and eosin (H\&E) and Masson's trichrome staining. Frozen sections (4- $\mu \mathrm{m}$ thick) were used for immunohistochemical staining. Three-step staining was applied for the following cytoskeletal proteins. ${ }^{18,19}$ The primary antibodies used were anti-alpha-dystroglycan (clone: VIA4-1, Upstate Biotechnology, Lake Placid, NY), anti-alpha-sarcoglycan, and antibeta-sarcoglycan (clone: Ad1/20A6 and bSarc/5B1, respectively, Novo Castra, United Kingdom). The second antibody was biotinylated rabbit antimouse antibody (K0675, DAKO, Carpinteria, 
Calif), followed by staining with fluorescein isothiocyanate-conjugated streptavidin (F0422, DAKO, Carpinteria, Calif). Each protein was viewed using an ECLIPSE TE 2000-U (Nikon, Japan) confocal microscope.

More than 5 sections were prepared for each specimen, and every stained sample was evaluated by 2 independent pathologists in a blinded manner. The percentage of the total area that was fibrotic, as determined by Masson's trichrome staining, was calculated by image analysis of the sections using a planimetric method with Windows MetaMorph software (Universal Imaging Corporation, Downingtown, Pa). The immunohistochemical signals were quantified by the same method, and the obtained values were expressed as a percentage of the value in F1B controls. At least 10 low-power fields per section were analyzed by the software.

Evaluation of Prognosis After HGF Gene Transfection We evaluated the lifesaving effect of the HGF gene transfection on the TO-2 hamsters, compared with culture medium injection and sham operation. The animals were randomly allocated to each treatment group and housed for 40 weeks after the operation. The survivals of the animals in the H, C, and S groups were calculated by the Kaplan-Meier method using SPSS Version 11.0 (SPSS Inc, Chicago Ill), and the significance of the difference among the groups at 40 weeks was tested by log-rank analyses.

\section{Statistical Analysis}

All values were expressed as the mean \pm SEM and subjected to multiple analysis of variance (ANOVA) using the StatView 5.0 program (Abacus Concepts, Berkeley, Calif). Echocardiographic data were first analyzed by 2-way repeated measurement ANOVA for differences across the whole time course, and 1-way ANOVA with the Tukey-Kramer post hoc test was used to verify the significance for the specific comparison at each time point. Other numeric data except for the survival were analyzed by 1-way ANOVA with the Tukey-Kramer post hoc test.

\section{Results}

\section{In Vivo HGF Gene Transfection of the Heart}

We measured the human HGF concentration in the transfected myocardium using an enzyme-linked immunosorbent assay. The expression of immunoreactive human HGF was marked in the $\mathrm{H}$ group myocardium, but not in that of the $\mathrm{C}$ group, 1 week after the operation (Figure 1). The HGF expression, however, was transient, given that only marginal levels of the protein were detected 3 weeks after the transfection.

\section{Improvement of Cardiac Function After HGF Gene Transfection}

Figure 2 shows cardiac function evaluated weekly by echocardiography. The Dd, Ds, and FS at 27 weeks of age were not significantly different between the $\mathrm{H}$ and $\mathrm{C}$ groups. After the operation, both the Dd and Ds were gradually enlarged and the FS was decreased in hamsters of the $\mathrm{C}$ group. Although the $\mathrm{Dd}$ of hamsters in the $\mathrm{H}$ group ap-

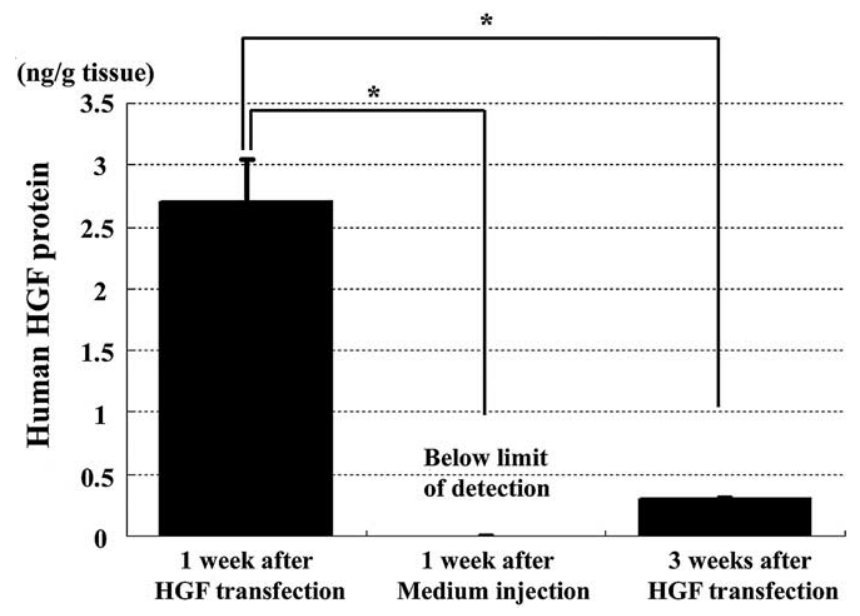

Figure 1. Detection of human hepatocyte growth factor (HGF) by enzyme-linked immunosorbent assay in transfected hearts. Human HGF protein was detected in hearts 1 week after transfection using the hemagglutinating virus of Japan (HVJ)-liposome method. The HGF expression, however, was transient; only marginal levels of the protein were detected 3 weeks after the transfection. ( $N=3$ for each group, ${ }^{*} P<.05$.)

peared slightly smaller than in the $\mathrm{C}$ group, it was also gradually enlarged. The progressive enlargement of the Ds observed in the $\mathrm{C}$ group, however, was delayed in the $\mathrm{H}$ group, and hamsters in the $\mathrm{H}$ group showed significantly smaller Ds and higher FS during the first 3 weeks after the operation compared with the $\mathrm{C}$ group. The effect of HGF transfection was transient, and the Ds began to increase and the FS to decrease by 4 weeks after the transfection.

\section{Morphologic Improvement of Cardiomyocytes After HGF Gene Transfection}

Figure 3, A illustrates typical examples of $H \& E$ and Masson-trichrome staining in the cardiomyocytes from F1B-strain (ie, normal) hamsters and from hamsters in the $\mathrm{H}$ and $\mathrm{C}$ groups 4 weeks after the operation. Although $\mathrm{H} \& \mathrm{E}$ staining did not show apparent differences between the $\mathrm{H}$ and C groups, the Masson's trichrome staining indicated there was less fibrosis in the hearts of the $\mathrm{H}$ group. Quantification of the fibrotic area confirmed this observation; the myocardial fibrosis of hamsters in the $\mathrm{H}$ group was significantly suppressed compared with that in the $\mathrm{C}$ group (Figure $3, \mathrm{~B})$.

Figure 4, A, shows representative immunohistochemical staining results for alpha-dystroglycan and for alpha- and beta-sarcoglycans in cardiomyocytes from F1B-strain hamsters. Alpha-dystroglycan and alpha- and beta-sarcoglycans were clearly detected in the sarcolemma of the F1B hamsters. In contrast, the TO-2 strain, in which the promoter lesion of the delta-sarcoglycan gene is deleted, failed to 

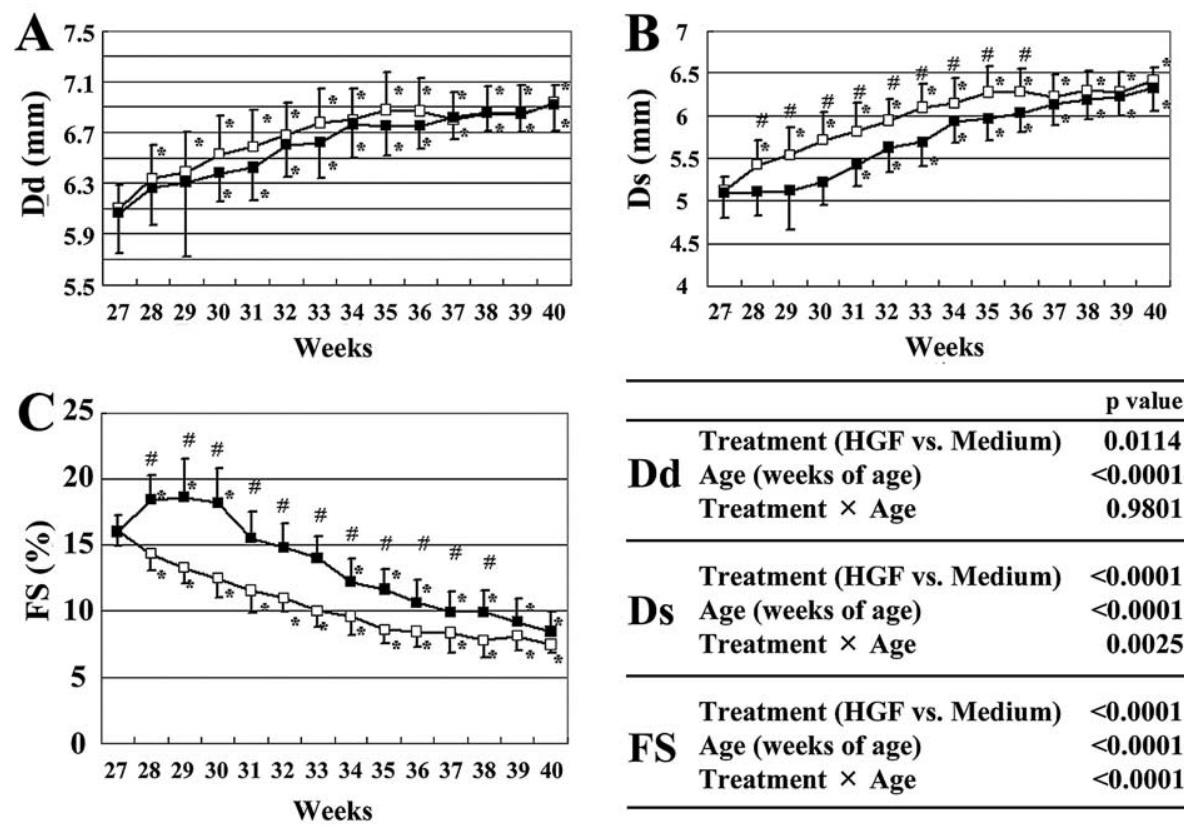

\begin{tabular}{|c|c|c|}
\hline & & p value \\
\hline \multirow{3}{*}{ Dd } & Treatment (HGF vs. Medium) & 0.0114 \\
\hline & Age (weeks of age) & $<0.0001$ \\
\hline & Treatment $\times$ Age & 0.9801 \\
\hline \multirow{3}{*}{ Ds } & Treatment (HGF vs. Medium) & $<0.0001$ \\
\hline & Age (weeks of age) & $<0.0001$ \\
\hline & Treatment $\times$ Age & 0.0025 \\
\hline \multirow{3}{*}{$\mathbf{F S}$} & Treatment (HGF vs. Medium) & $<0.0001$ \\
\hline & Age (weeks of age) & $<0.0001$ \\
\hline & Treatment $\times$ Age & $<0.0001$ \\
\hline
\end{tabular}

Figure 2. Cardiac performance. $A$ and $B$, Left ventricular end-diastolic dimension (Dd) and left ventricular end-systolic dimension (Ds) measured by echocardiography. C, Fractional shortening (FS) calculated using the Dd and Ds. Both the Dd and Ds were gradually enlarged, and FS was decreased in hamsters of the $\mathrm{C}$ group. However, hamsters in the $\mathbf{H}$ group showed a slightly smaller Dd, significantly smaller Ds, and higher FS during the first 3 weeks after the operation compared with these values in the $\mathbf{C}$ group. The effect of HGF transfection was transient, and the Ds began to increase and FS began to decrease by 4 weeks after the transfection. $H$ group (solid boxes); C group (open boxes). ( ${ }^{*} P<.05$ vs before operation [27 weeks old]; $\# P<.05$ vs $C$ group.)

express not only delta-sarcoglycan but also alpha-, beta-, and gamma-sarcoglycans. ${ }^{19}$ In addition, it was reported that alpha-dystroglycan dissociates from beta-dystroglycan and the other components of the dystrophin-glycoprotein complex in mature cardiomyopathic hamsters. ${ }^{20-22}$ Figure $4, \mathrm{~B}$ confirms these results in the TO-2 hamsters of the $\mathrm{C}$ group. It is interesting that in the H-group TO-2 hamsters, alphadystroglycan and alpha- and beta-sarcoglycans were readily detected 2 weeks after the operation (Figure 4, C). However, 8 weeks after the operation, none of these proteins were detectable in the $\mathrm{H}$ group (Figure 4, D).

Figure 5 shows the quantitative analysis of the immunohistologic signals shown in Figure 4. The area in which there were above-background green signals in the indicated group was compared with that of F1B hamsters, and the relative level of expression for each protein is shown. Although none of the signals for any of the 3 proteins reached the normal levels observed in F1B hamsters 2 weeks after the operation, the signals were significantly higher in the $\mathrm{H}$ group than in the $\mathrm{C}$ group. Thus, weak but significant expression of all 3 proteins was transiently observed 2 weeks after HGF transfection.

\section{Prolongation of Life Expectancy After HGF Gene Transfection}

Hamsters treated with culture medium or a sham operation (C or S group) started to die 1 week after the operation, and the number of surviving animals decreased gradually over the 4- to 10 -week period after the operation (Figure 6). There was no significant difference in survival between the $\mathrm{C}$ and $\mathrm{S}$ groups $(P=.8029)$. In contrast, almost all of the hamsters treated with HGF gene transfection ( $\mathrm{H}$ group) survived for the full 40 weeks, and the $\mathrm{H}$ group showed significantly better survival. The 40 -week survival percentages for the $\mathrm{H}, \mathrm{C}$, and $\mathrm{S}$ groups were $84.2 \%, 43.8 \%$, and $47.9 \%$, respectively $(P=.0029$ for $\mathrm{H}$ vs $\mathrm{C}$ groups, $P=$ .0128 for $\mathrm{H}$ vs $\mathrm{S}$ groups). Therefore, we conclude that the life expectancy of the TO-2 hamsters was prolonged by the HGF gene transfection.

\section{Discussion}

The present study demonstrated an improvement in the life expectancy of adult cardiomyopathic hamsters by HGF gene transfection. The improvement was associated with a transient reorganization of the cytoskeletal proteins, reduction of myocardial fibrosis, and transient delay in the dete- 

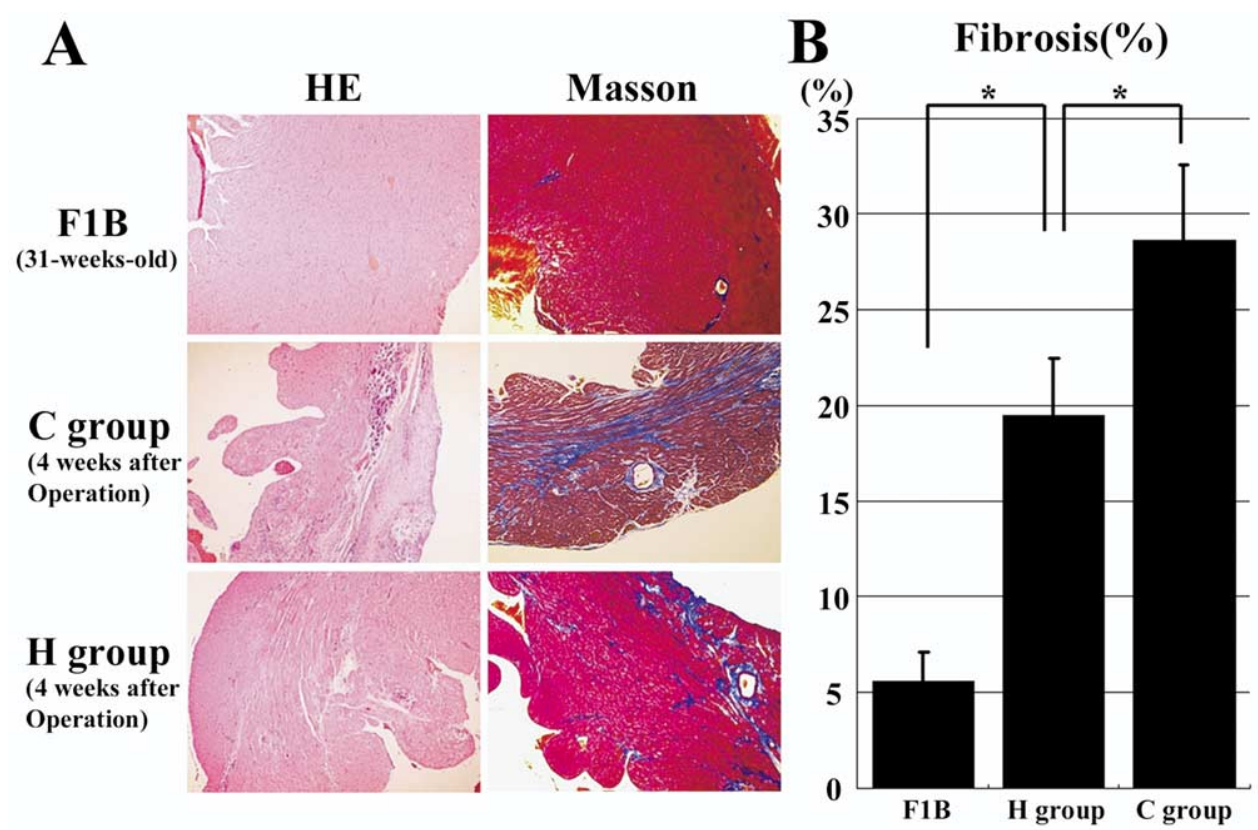

Figure 3. Suppression of fibrotic change in the left ventricle of TO-2 hamsters by HGF. Tissue sections were stained by hematoxylin-eosin (H\&E) or Masson-trichrome dye. The fibrous area was quantified by image analysis in tissue sections stained with Masson-trichrome. The percentage of fibrosis in the $\mathbf{H}$ group was significantly suppressed compared with that in the $C$ group. ( $N=5$ for each group, ${ }^{*} P<.05$.)

rioration of cardiac performance. These findings suggest that the morphologic improvements induced by a growth factor such as HGF may be a therapeutic strategy for temporarily restoring the impaired heart in human DCM.

The TO-2 hamster strain is a representative model of human hereditary DCM in which the promoter region of the delta-sarcoglycan gene is deleted; this hamster fails to express alpha-, beta-, gamma-, or delta-sarcoglycan. ${ }^{19,23,24}$ Furthermore, in this hamster strain, the number of cardiomyocytes decreases progressively after birth, and cardiac remodeling, which mainly consists of myocardial fibrosis, occurs with ventricular dilatation and thinning, leading to progressive congestive heart failure; these animals start to die when they are approximately 30 weeks old. ${ }^{25}$

HGF is a pleiotropic growth factor that shows, at least, antifibrotic, angiogenic, and antiapoptotic effects. ${ }^{10,11} \mathrm{We}$ have already reported that HGF has a cardioprotective effect because of its antiapoptotic effect on cardiomyocytes, which is associated with a marked expression of Bcl-xL in injured cardiomyocytes. ${ }^{26}$

In addition, Taniyama and colleagues ${ }^{12}$ reported that HGF expression may participate in the prevention of myocardial injury through antifibrotic and angiogenetic action by up-regulation of matrix metalloproteinase (MMP)-1 in a different hamster model of DCM. In this study, the myocardial fibrosis was significantly reduced after HGF gene transfection. Therefore, one explanation for the reduction of the progressive decrease in cardiac performance in the hamster model of DCM is the antifibrotic and probably antiapoptotic effects elicited by HGF.

Another important effect of HGF is to induce an appropriate microenvironment for ECM remodeling, including a strong expression of cytoskeletal proteins such as alpha- and beta-dystroglycan. ${ }^{13}$ The DGC is composed of dystrophin, the dystroglycans (alpha-, beta-subunits), the sarcoglycans (alpha-, beta-, gamma-, delta-subunits), sarcospan, the dystrobrevins, and the syntrophins. ${ }^{14,27}$ This DGC component serves as a link between the intracellular cytoskeleton and the ECM. Although the precise function of the DGC has not been elucidated, the current main hypothesis is that it has a mechanical function to strengthen the plasma membrane during heart muscle contraction. ${ }^{4}$ In addition, several lines of evidence suggest another important role for the DGC in signal transduction pathways, which it appears to share with the syntrophins and/or calmodulin. ${ }^{14}$

In this study, immunohistochemical staining demonstrated the expression of alpha- and beta-sarcoglycans in the $\mathrm{H}$ group, whereas there was no expression of these proteins in the $\mathrm{C}$ group, although the mechanism of the reconstitution of these proteins by HGF is unknown. Concomitant loss of all the sarcoglycans causes the contraction-induced dam- 


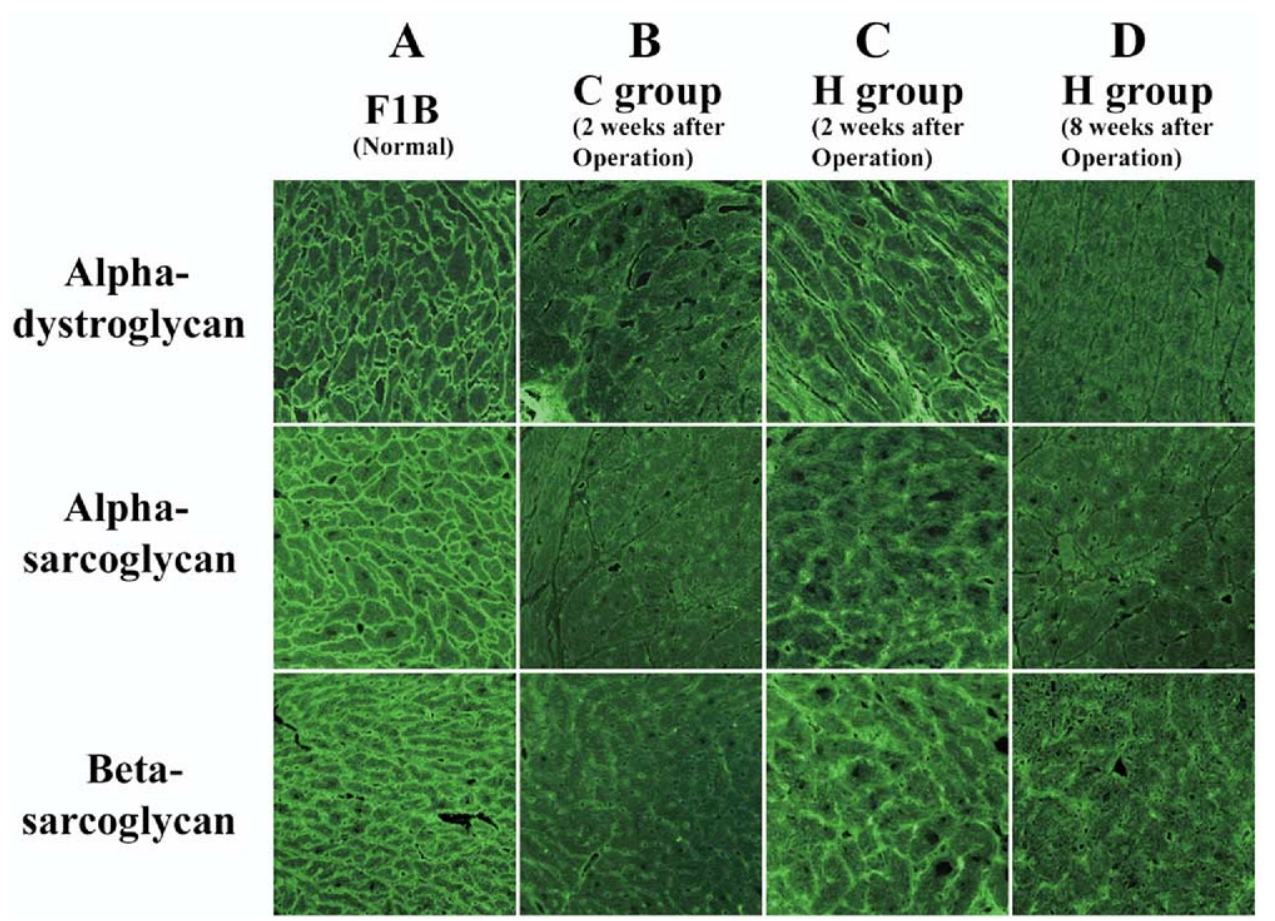

Figure 4. Immunostaining for alpha-dystroglycan and alpha- and beta-sarcoglycans in cardiomyocytes. A, FIB hamster, 27 weeks old; B, C-group hamster 2 weeks after the operation; C, H-group hamster 2 weeks after the operation; D, H-group hamster, 8 weeks after the operation. Alpha-dystroglycan, and alpha- and beta- sarcoglycans were clearly detected in the sarcolemma of the F1B strain hamsters (A). In the C group, neither dystroglycan nor sarcoglycans was detected (B). In contrast, in the $\mathbf{H}$ group, cardiomyocytes expressed alpha-dystroglycan, and alpha- and beta-sarcoglycans 2 weeks after the transfection (C), but this expression disappeared by 8 weeks after the transfection (D).

age of cardiomyocytes, but the expression of sarcoglycans, even in small amounts, prevents this damage in a mouse model. ${ }^{28}$ Taking all this information together, we speculate that the transient expression of the alpha- and beta-sarcoglycans induced by HGF may be associated with reduction of the myocardial damage and that such a reduced damage may contribute to the subsequent attenuation of myocardial fibrosis and/or the delay in deterioration of cardiac performance.

In addition, immunohistochemical staining of cardiomyocytes demonstrated the re-expression of alpha-dystroglycan in group H. Yamada and colleagues ${ }^{29}$ suggested 2 possible mechanisms for the dissociation of alpha-dystroglycan from betadystroglycan in sarcoglycanopathy, which is characterized by a deficiency of the sarcoglycan complex because of primary defects in the genes for these proteins. One mechanism is that MMPs, which degradate ECM activity, might be responsible for processing beta-dystroglycan, and the other mechanism is that the sarcoglycan complex might mask the MMP cleavage site on beta-dystroglycan in normal muscle. ${ }^{29}$ But the deficiency of the sarcoglycan complex in sarcoglycanopathy ex- poses the cleavage site and induces the MMPs processing of beta-dystroglycan. ${ }^{29}$ From these reports we speculate that the reconstitution of alpha-dystroglycan into the membrane fraction may occur because the sarcoglycans expressed after transfection with the HGF gene may mask the MMP cleavage site on beta-dystroglycan and/or MMP activity may be inhibited by HGF.

Moreover, alpha-dystroglycan is connected to laminin extracellularly. Cell-matrix interactions mediated by laminin and integrin elicit various cell functions, such as proliferation, differentiation, motility, and protein production. ${ }^{23}$ $\mathrm{HGF}$ is known to modulate the laminin/integrin interactions to enhance cell-cell and cell-ECM interactions. ${ }^{23}$ Although we did not immunolabel integrin and laminin in this study, laminin activity enhanced by HGF may have played an important role in the histologic and functional recovery of cardiomyocytes in the TO-2 hamsters.

We showed that the life expectancy of the TO-2 hamsters was prolonged by transfection with the HGF gene. Several reports have shown that the life expectancy of TO-2 hamsters is significantly prolonged by delta-sarcoglycan gene transfec- 


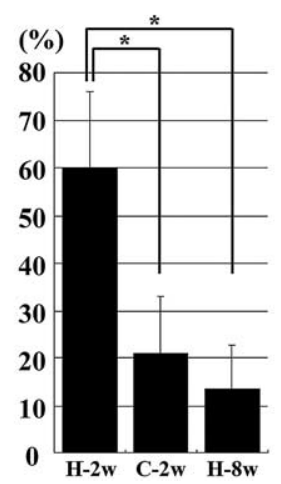

A Alphadystroglycan

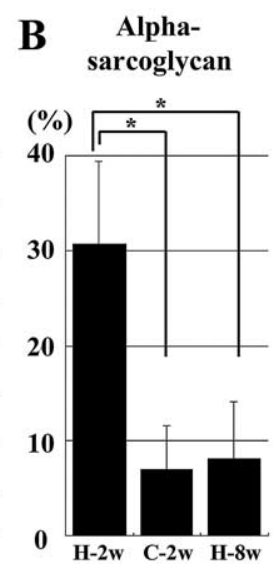

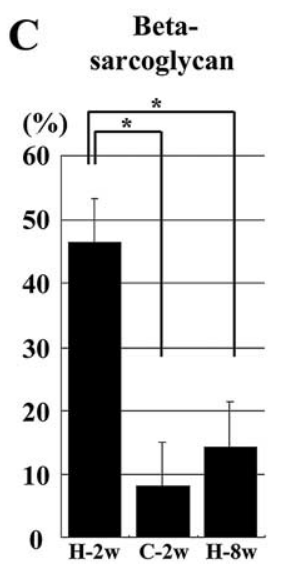

Figure 5. Quantitative results of the immunohistologic signals shown in Figure 4. A, Alpha-dystroglycan. B, Alpha-sarcoglycan. C, Beta-sarcoglycan. Although the signals for all 3 proteins had not reached the normal levels observed in F1B mice 2 weeks after the operation, they were significantly higher in the $H$ group than in the $\mathrm{C}$ group. (H-2w, 2 weeks after the operation in the $\mathrm{H}$ group; $\mathrm{H}-8 \mathrm{w}, 8$ weeks after the operation in the H group; C-2w, 2 weeks after the operation in the $\mathrm{C}$ group; $\mathbf{N}=\mathbf{5}$ for $\mathrm{H}-2 \mathrm{w}$ and $\mathrm{C}-2 \mathrm{w}, \mathbf{N}=$ 3 for $\mathrm{H}-8 \mathrm{w},{ }^{*} \boldsymbol{P}<$.05.)

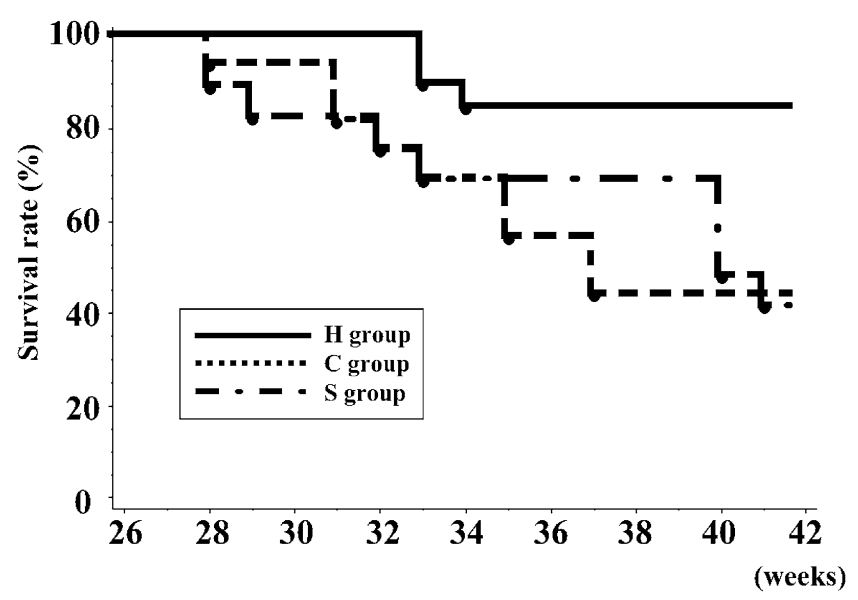

Figure 6. Survivals. The percentage of surviving animals at $\mathbf{4 0}$ weeks was $84.2 \%$ for the $\mathrm{H}$ group, $\mathbf{4 3 . 8 \%}$ for the $\mathrm{C}$ group, and $47.9 \%$ for the $S$ group. There was no significant difference between the $C$ and $S$ groups, but there was a significant difference between the $H$ and $C$ groups. (H group, $N=19$; $C$ group, $N=16$; $S$ group, $\mathbf{N}=18$.)

tion and oral therapy with the angiotensin-converting enzyme inhibitor enalapril. ${ }^{25,30}$ In these reports, the treatments were started at 5 and 6 weeks of age, respectively, before cardiac function was impaired. Here, the HGF treatment was given when the hamsters were 27 weeks old. It is very interesting that even at such a late phase of DCM, transfection with the HGF gene induced the reorganization of the cytoskeletal proteins, leading to an improvement in the cardiac performance of the impaired heart.

The disadvantage of using the HVJ-liposome method to transfect HGF is that the secretion of HGF is sustained for only a few weeks after the transfection; we believe that the loss of HGF expression explains the gradual decrease in cardiac function we observed, which started 4 weeks after the surgery. Therefore, longer-term HGF secretion methods must be considered to maintain the cardiac function, such as the repeated administration of HGF or a slow-release delivery system. Further investigation is needed to determine the best approach for clinical applications.

In summary, transfection with the HGF gene induced transient morphologic improvement, including the reduction of myocardial fibrosis and reorganization of the cytoskeletal proteins in a hamster model of DCM; these changes led to a delay in the deterioration of cardiac performance and an improvement in life expectancy.

We thank Akiko Nishimura, Masako Yokoyama, and Aiko Miki for their excellent technical assistance.

\section{References}

1. Abelmann WH, Lorell BH. The challenge of cardiomyopathy. $J$ Am Coll Cardiol. 1989;13:1219-39.

2. Towbin JA, Bowles NE. The failing heart. Nature. 2002;415:227-33.

3. Packer M, Bristow MR, Cohn JN, Colucci WS, Fowler MB, Gilbert EM, et al. The effect of carvedilol on morbidity and mortality in patients with chronic heart failure. U.S. Carvedilol Heart Failure Study Group. N Engl J Med. 1996;334:1349-55.

4. Packer M, O'Connor CM, Ghali JK, Pressler ML, Carson PE, Belkin $\mathrm{RN}$, et al. Effect of amlodipine on morbidity and mortality in severe chronic heart failure. Prospective Randomized Amlodipine Survival Evaluation Study Group. N Engl J Med. 1996;335:1107-14.

5. Hosenpud JD, Bennett LE, Keck BM, Fiol B, Boucek MM, Novick RJ. The Registry of the International Society for Heart and Lung Transplantation: fifteenth official report-1998. J Heart Lung Transplant. 1998;17:656-68.

6. Bowles NE, Bowles KR, Towbin JA. The "final common pathway" hypothesis and inherited cardiovascular disease. The role of cytoskeletal proteins in dilated cardiomyopathy. Herz. 2000;25:168-75.

7. Vatta M, Stetson SJ, Perez-Verdia A, Entman ML, Noon GP, TorreAmione G, et al. Molecular remodelling of dystrophin in patients with end-stage cardiomyopathies and reversal in patients on assistancedevice therapy. Lancet. 2002;359:936-41.

8. Frazier $\mathrm{OH}$, Myers TJ. Left ventricular assist system as a bridge to myocardial recovery. Ann Thorac Surg. 1999;68:734-41.

9. Hetzer R, Muller J, Weng Y, Wallukat G, Spiegelsberger S, Loebe M. Cardiac recovery in dilated cardiomyopathy by unloading with a left ventricular assist device. Ann Thorac Surg. 1999;68:742-9.

10. Taniyama Y, Morishita R, Aoki M, Nakagami H, Yamamoto K, Yamazaki $\mathrm{K}$, et al. Therapeutic angiogenesis induced by human hepatocyte growth factor gene in rat and rabbit hindlimb ischemia models: preclinical study for treatment of peripheral arterial disease. Gene Ther. 2001;8:181-9.

11. Liu Y, Rajur K, Tolbert E, Dworkin LD. Endogenous hepatocyte growth factor ameliorates chronic renal injury by activating matrix degradation pathways. Kidney Int. 2000;58:2028-43.

12. Taniyama Y, Morishita R, Aoki M, Hiraoka K, Yamasaki K, Hashiya $\mathrm{N}$, et al. Angiogenesis and antifibrotic action by hepatocyte growth factor in cardiomyopathy. Hypertension. 2002;40:47-53. 
13. Miyagawa S, Sawa Y, Taketani S, Kawaguchi N, Nakamura T, Matsuura $\mathrm{N}$, et al. Myocardial regeneration therapy for heart failure: hepatocyte growth factor enhances the effect of cellular cardiomyoplasty. Circulation. 2002;105:2556-61.

14. Straub V, Campbell KP. Muscular dystrophies and the dystrophinglycoprotein complex. Curr Opin Neurol. 1997;10:168-75.

15. Seki T, Hagiya M, Shimonishi M, Nakamura T, Shimizu S. Organization of the human hepatocyte growth factor-encoding gene. Gene. 1991;102:213-9.

16. Kaneda Y, Iwai K, Uchida T. Expression of DNA cointroduced with nuclear protein in adult rat liver. Science. 1989;243:375-8.

17. Yamada A, Matsumoto K, Iwanari H, Sekiguchi K, Kawata S, Matsuzawa Y, et al. Rapid and sensitive enzyme-linked immunosorbent assay for measurement of HGF in rat and human tissues. Biomed Res. 1995;16:105-14.

18. Kawada T, Sakamoto A, Nakazawa M, Urabe M, Masui F, Hemmi C, et al. Rescue of hereditary form of dilated cardiomyopathy by rAAVmediated somatic gene therapy: amelioration of morphological findings, sarcolemmal permeability, cardiac performances, and the prognosis of TO-2 hamsters. Biochem Biophys Res Commun. 2001;284: 431-5.

19. Sakamoto A, Ono K, Abe M, Jasmin G, Eki T, Murakami Y, et al. Both hypertrophic and dilated cardiomyopathies are caused by mutation of the same gene, delta-sarcoglycan, in hamster: an animal model of disrupted dystrophin-associated glycoprotein complex. Proc Natl Acad Sci U S A. 1997;94:13873-8.

20. Roberds SL, Ervasti JM, Anderson RD, Ohlendieck K, Kahl SD, Zoloto D, et al. Disruption of the dystrophin-glycoprotein complex in the cardiomyopathic hamster. J Biol Chem. 1993;268:11496-9.

21. Iwata Y, Nakamura H, Mizuno Y, Yoshida M, Ozawa E, Shigekawa M. Defective association of dystrophin with sarcolemmal glycoproteins in the cardiomyopathic hamster heart. FEBS Lett. 1993; 329:227-31.
22. Straub V, Duclos F, Venzke DP, Lee JC, Cutshall S, Leveille CJ, et al. Molecular pathogenesis of muscle degeneration in the delta-sarcoglycan-deficient hamster. Am J Pathol. 1998;153:1623-30.

23. Bajusz E, Baker JR, Nixon CW, Homburger F. Spontaneous, hereditary myocardial degeneration and congestive heart failure in a strain of Syrian hamsters. Ann N Y Acad Sci. 1969;156:105-29.

24. Nigro V, Okazaki Y, Belsito A, Piluso G, Matsuda Y, Politano L, et al. Identification of the Syrian hamster cardiomyopathy gene. Hum Mol Genet. 1997;6:601-7.

25. Shimizu T, Okamoto H, Chiba S, Matsui Y, Sugawara T, Akino M, et al. VEGF-mediated angiogenesis is impaired by angiotensin type 1 receptor blockade in cardiomyopathic hamster hearts. Cardiovasc Res. 2003;58:203-12.

26. Nakamura T, Mizuno S, Matsumoto K, Sawa Y, Matsuda H, Nakamura T. Myocardial protection from ischemia/reperfusion injury by endogenous and exogenous HGF. J Clin Invest. 2000;106:1511-9.

27. Campbell KP. Three muscular dystrophies: loss of cytoskeleton-extracellular matrix linkage. Cell. 1995;80:675-9.

28. Hack AA, Lam MY, Cordier L, Shoturma DI, Ly CT, Hadhazy MA, et al. Differential requirement for individual sarcoglycans and dystrophin in the assembly and function of the dystrophin-glycoprotein complex. J Cell Sci. 2000;113:2535-44.

29. Yamada H, Saito F, Fukuta-Ohi H, Zhong D, Hase A, Arai K, et al. Processing of beta-dystroglycan by matrix metalloproteinase disrupts the link between the extracellular matrix and cell membrane via the dystroglycan complex. Hum Mol Genet. 2001;10:1563-9.

30. Kawada T, Nakazawa M, Nakauchi S, Yamazaki K, Shimamoto R, Urabe M, et al. Rescue of hereditary form of dilated cardiomyopathy by rAAV-mediated somatic gene therapy: amelioration of morphological findings, sarcolemmal permeability, cardiac performances, and the prognosis of TO-2 hamsters. Proc Natl Acad Sci U S A. 2002;99: 901-6. 